\title{
Latent avoidance learning: Positive transfer from barpress to shuttle avoidance and vice versa
}

\author{
SAM S. RAKOVER \\ University of Haifa, Mount Carmel, Israel
}

\begin{abstract}
Rats typically show very slow improvement on barpress-avoidance tasks, but they show rapid improvement on shuttle-avoidance tasks. This phenomenon can be due either to an inability of rats to learn barpress avoidance or to interference from competing responses (e.g., freezing and withdrawal) that hinder the performance of the barpress-avoidance response, but not the shuttleavoidance response. The results of the present experiment, which employed a transfer of learning design from barpress avoidance to shuttle avoidance and vice versa, support the latter hypothesis.
\end{abstract}

Typically, rats have great difficulty in learning barpressavoidance tasks, but they learn shuttle-avoidance tasks easily. I shall refer to this as the bar-shuttle avoidance phenomenon. In a barpress-avoidance task, the rat has to press a lever in a Skinner box when a warning signal appears in order to avoid a footshock. In a shuttle-avoidance task, the rat has to cross from one chamber to an adjacent one when a warning signal appears. Hence, the difference between these two tasks is in the response to be learned: a barpress in the first task and locomotion in the second. This phenomenon has also been found in fish (e.g., Rakover, 1979).

Meyer, Cho, and Weseman (1960) were the first to point out that barpress avoidance is learned very slowly. Since 1960, this fact has become well known, although certain variables, such as discontinuous low shocks and short intertrial intervals, have been found to somewhat facilitate barpress avoidance (e.g., D'Amato, Keller, \& DiCara, 1964; Hurwitz, 1964; Rakover, 1980). By contrast, one-way avoidance or shuttle avoidance is learned easily (for review, see Bolles, 1975; Mackintosh, 1983).

The bar-shuttle avoidance phenomenon can be explained in terms of freezing and withdrawal (flight) responses. These responses are elicited by a warning signal, which functions also as a conditioned fear-arousing stimulus (e.g., a light previously paired with a shock), in a way similar to the elicitation of a reflex action. While freezing is conceived of as an inborn immobile response to a fear-arousing stimulus, withdrawal is aroused by the rat's finding a way to escape from the source of fear, although

This research was supported by Haifa University's research authority and the faculty of social science and mathematics. The writing of the article was funded by the Department of Psychology, Oakland University, Rochester, MI. The author is very grateful to Ted Landau, Ruth Nathan, and Larry Nathan for their helpful comments on an earlier draft of this paper.

Requests for reprints should be addressed to the author at the Department of Psychology, University of Haifa, Mount Carmel, 31999, Israel. it is viewed also as an innate response. That is, withdrawal is the rat's innate tendency to increase the distance between itself and the fear-arousing stimulus. It is suggested that although freezing and withdrawal interfere with the rat's performing of barpress avoidance, withdrawal enhances shuttle avoidance. In the barpress-avoidance situation, freezing and withdrawal are incompatible with the avoidance response required. In the shuttle-avoidance situation, withdrawal is compatible with the avoidance response, since both withdrawal and avoidance involve the rat's escaping from the fear compartment to the safe adjacent one (e.g., Blanchard \& Blanchard, 1969; Kreickhaus, Miller, \& Zimmerman, 1965; Rakover, 1975, 1980, 1984).

In view of this, one may propose the hypothesis-the fear interference hypothesis-that poor barpress avoidance is to be attributed not to the rat's difficulties or inability to learn the avoidance information (i.e., to learn the avoidance contingency), but to its inability to execute it. The rat simply cannot act in accordance with the avoidance information it has acquired, because of the strong interference coming from the freezing and withdrawal responses elicited by the fear. Put another way, in barpress avoidance, the warning signal has two major opposing effects. One effect concerns the avoidance information: if the rat would perform the required response when the warning signal appears, then it would avoid the shock. The second effect results from the warning signal's functioning as a fear-arousing stimulus, which elicits freezing and withdrawal, blocking the barpress avoidance.

If this account is correct, then one way to reveal the latent barpress-avoidance information is to let the rat learn a subsequent, easier avoidance task, such as a shuttle avoidance. Since in both these tasks the rat has to learn the avoidance contingency, one would predict a positive bar-shuttle transfer. Accordingly, subsequent shuttleavoidance performance of the rats in an experimental group that previously learned barpress avoidance (with 
the usual poor performance) will be better than that of rats in a control group that did not previously learn barpress avoidance (e.g., Rakover, 1984).

Similarly, there is the possibility of obtaining a positive shuttle-bar transfer (i.e., finding out whether the acquisition and performing of a shuttle avoidance would enhance a subsequent barpress avoidance). In comparison with the previously mentioned transfer, which examines whether covert barpress-avoidance information facilitates subsequent shuttle avoidance, the shuttle-bar transfer examines whether overt shuttle avoidance facilitates the performance of subsequent barpress avoidance in spite of the strong interference coming from the fear reactions.

Although learning the avoidance contingency would account for the positive transfer from task to task, there is at least one factor that can contribute to a negative transfer. As mentioned before, the warning signal elicits fear in addition to its providing the rat with the information about the avoidance contingency. Hence, a nonnaive rat that had previous experience with an avoidance task may exhibit greater fear in the beginning of learning a subsequent new avoidance task than does a naive rat. The higher the fear in starting to learn a subsequent new avoidance task, the stronger the interference with the new learning through the elicitation of freezing and withdrawal. This process may result in a negative transfer. To the author's knowledge, research on latent avoidance learning has not been reported.

\section{METHOD}

\section{Subjects}

Sixty male rats were randomly assigned to two groups, each containing 30 rats. The rats were a variation of the Albino Wistar strain, were approximately 2.8 months old, and weighed approximately $320 \mathrm{~g}$. The rats had free access to food and water.

\section{Apparatus}

There were two apparatuses: a Skinner box and a shuttlebox, each one housed in a sound-attenuating chamber. A standard Skinner box was used (length $\times$ width $\times$ height $=30 \times 30 \times 30 \mathrm{~cm}$ ). The floor was made of a grid of steel bars that were $0.5 \mathrm{~cm}$ in diameter and spaced $1 \mathrm{~cm}$ apart and that could be electrified. The walls were made of transparent Perspex, and the ceiling was made of a milky Perspex. The warning signal was a light, a 25-W, 24-V electric bulb, attached outside the box, above the center of the ceiling.

The shuttlebox consisted of two identical boxes and two stainless steel trapeze-like box covers. A 25-W, 24-V electric light, used as the warning signal, was attached to the center of each cover. The bottom of the cover, which was the ceiling of the box, was made of white translucent plastic. The box's dimensions were $20 \times 11 \times 31 \mathrm{~cm}$ (length $\times$ width $x$ height). The floor consisted of 18 bars of steel, $0.5 \mathrm{~cm}$ in diameter and spaced at $1.1 \mathrm{~cm}$, connected along both sides by Pertinax. A steel pole, on which a weight could be moved, was connected to the center of the back Pertinax. The weight of the floor on one side and the weight of the pole on the other side together formed two arms of a lever with an up-and-down swinging range of $0.5 \mathrm{~cm}$ and a rotation axis made by the back Pertinax, which was supported by two points. A weight of $200 \mathrm{~g}$ or more on the floor pressed it downward. The lever movements were used to detect the rat as it crossed from one compartment to the other.

Between the two boxes there was a 5-cm fence made of two rows of steel bars attached to each other; the bars were identical in size to those used inside the boxes. The gap between these two rows was $0.5 \mathrm{~cm}$. In order to prevent the rat from clinging to the fence as it crossed from box to box, an electric current of the same intensity as that passing through the grid also passed through the two top strips of the fence. The electric shock (1 mA) was produced by a solid-state shocker/scrambler (Lehigh Valley Electronics).

\section{Design and Procedure}

Two major transfer groups were used. In the first, the bar-shuttle transfer group, rats were first trained to avoid a shock by a barpress, and then they were transferred to the subsequent shuttle-avoidance task. In the second, the shuttle-bar transfer group, rats were first trained to avoid a shock in the shuttle-avoidance task, and then they were transferred to the subsequent barpress-avoidance task. Two measures were calculated for each rat: percent of shuttle avoidance and percent of barpress avoidance. To facilitate the statistical analysis, the two transfer groups with two measures per group are treated as four groups as follows: (1) The bar-(shuttle) group refers to the $\mathbf{3 0}$ rats in the bar-shuttle transfer group, when the measure reported (in parentheses) is percent shuttle avoidance. (2) The (bar)-shuttle group refers to the same 30 rats in the bar-shuttle transfer group, when the measure reported (in parenthesis) is percent barpress avoidance. The (3) (shuttle)-bar and (4) shuttle-(bar) groups were similarly constructed (the words in the parentheses indicate the type of measure reported). Group 3 is considered as a control group to the first experimental group (Group 1), and Group 2 is considered as a control group to the second experimental group (Group 4).

Except for the difference in the apparatuses and the response required, the avoidance procedure was identical. In the avoidance contingency, the duration of the warning signal was $15 \mathrm{sec}$. A press on the lever, or a crossing over, terminated the warning signal, prevented the footshock and initiated the rest period, the intertrial interval of $45 \mathrm{sec}$. A failure to avoid initiated the escape contingency. The rat received a continuous footshock (with a maximum of $2 \mathrm{~min}$ ), which lasted until the rat pressed the lever or crossed over. The escape terminated the warning signal simultaneously with the shock and initiated the rest period of $45 \mathrm{sec}$. Each trial started with the appearance of the warning signal. In the shuttle box, the warning signal appeared in the box occupied by the rat. The barpress training consisted of 10 consecutive days, 60 trials per day for each rat, whereas the shuttle-avoidance training consisted of 12 consecutive days. ${ }^{1}$

\section{RESULTS}

As can be seen in Figure 1, during the first 10 days of training, shuttle avoidance was much easier to learn than was barpress avoidance $[t(58)=4.61, p<.001$ for (shuttle)-bar vs. (bar)-shuttle, and $t(58)=5.53$, $p<.001$ for bar-(shuttle) vs. shuttle-(bar)]. The bar(shuttle) experimental group learned shuttle avoidance bet-

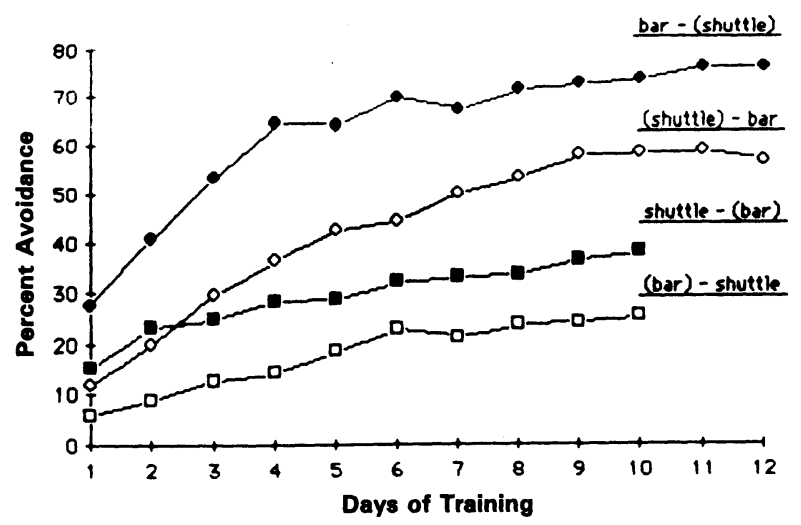

Figure 1. Percent avoidance of the bar-(shuttle) experimental group and the (shuttle)-bar control group and of the shuttle-(bar) experimental group and the (bar)-shuttle control group, as a function of days of training. 
ter than did the (shuttle)-bar control group, indicating a positive transfer of avoidance information from the barpress task to the shuttle-avoidance task $[F(1,58)=13.15$, $p<.001]$; however, the interaction differences between these groups are not significant $[F(11,638)=1.08$, $p>.05]$. In comparison to the (shuttle)-bar control group, the experience of the bar-(shuttle) experimental group with the barpress avoidance enhanced subsequent shuttle avoidance by an average of 11.75 avoidances.

The shuttle-(bar) experimental group learned barpress avoidance better than did the (bar)-shuttle control group, indicating a positive transfer of avoidance information from the shuttle-avoidance task to the barpress task $[F(1,58)=5.33, p<.05]$; however, the interaction differences between these two groups are not significant $[F(9,522)>1]$. In comparison to the (bar)-shuttle control group, the acquisition of shuttle avoidance by the shuttle-(bar) experimental group improved subsequent barpress avoidance by an average of 6.96 avoidances.

Figure 2 presents subsequent avoidance performance as a function of previous avoidance. Panel A depicts the relationship between two measures of the bar-shuttle transfer group. These measures, calculated for each one of the 30 rats, are (1) overall percent previous barpress avoidance and (2) overall percent subsequent shuttle avoidance. The abscissa consists of six subgroups of the 30 rats, $1 \mathrm{~A}-6 \mathrm{~A}$. The rats were divided into these subgroups on the basis of the actual distribution of percent previous barpress avoidance. An attempt was made to equalize both the range of percent barpress avoidance and the number of rats per subgroup. The ordinate consists of the mean percent subsequent shuttle avoidance, corresponding to each one of the six subgroups. Panel B depicts a similar relationship between the following two measures of the shuttle-bar transfer group: overall per-

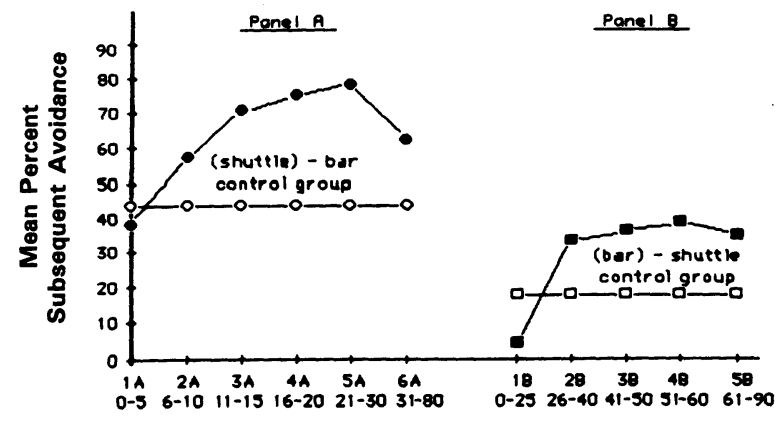

Percent Previous Avoidance

Figure 2. Mean percent subsequent avoidance as a function of percent of previous avoidance. Panel A shows the relation between subsequent bar-(shuttle) and previous (bar)-shuttle groups and the mean avoidance performance of the (shuttle)-bar control group. The distribution of previous (bar)-shuttle percent avoidance is broken into six subgroups, $1 \mathrm{~A}-6 \mathrm{~A}$, where the numbers give the range of percent avoidance of each subgroup. Panel B shows the relation between subsequent shuttle-(bar) and previous (shuttle)-bar groups and the mean avoidance performance of the (bar)-shuttle control group. The distribution of previous (shuttle)-bar percent avoidance is broken into five subgroups, 1B-5B, where numbers give the range of percent avoidance of each subgroup. cent previous shuttle avoidance and overall percent subsequent barpress avoidance. The former distribution is broken into five subgroups, 1B-5B.

As can be seen from Figure 2, Panel A, subsequent shuttle avoidance tends to increase until an optimum value is reached and then to decrease as a function of previous barpress avoidance $[F(5,24)=4.77, p<.01]$. In comparison to the (shuttle)-bar control group, previous barpress avoidance enhanced subsequent shuttle avoidance only for subgroups $3 \mathrm{~A}, 4 \mathrm{~A}$, and $5 \mathrm{~A}$. (The differences between subgroups $3 \mathrm{~A}, 4 \mathrm{~A}, 5 \mathrm{~A}$, and the (shuttle)-bar control group are significant $[F(1,53)=10.32, p<.01$; $F(1,53)=14.04, p<.01 ;$ and $F(1,53)=11.83$, $p<.01$, respectively]. The differences between subgroups 1A, 2A, 6A, and the (shuttle)-bar control group are not significant.) This means that in comparison to the (shuttle)-bar control group, even $11 \%$ to $15 \%$ barpress avoidance (which is rather a poor performance) is sufficient to enhance shuttle avoidance by about $27 \%$.

Similar results have been obtained with respect to the effect of shuttle avoidance on subsequent barpress avoidance (see Figure 2, Panel B). Subsequent barpress avoidance tends to increase until an optimum value is reached and then to decrease slightly as a function of previous shuttle-bar avoidance $[F(4,25)=7.81$, $p<.01]$. In comparison to the (bar)-shuttle control group, previous shuttle-avoidance experience had a negative effect on subsequent barpress-avoidance performance in Subgroup 1B $[F(1,54)=4.63, p<.05]$ and had positive effects in Subgroups 2B, 3B, 4B, and 5B [ $F(1,54)$ $=5.98, p<.05 ; F(1,54)=10.65, p<.01 ; F(1,54)$ $=10.70, p<.01 ; F(1,54)=5.11, p<.05$, respectively]. This means that in comparison to performance of the (bar)-shuttle control group, the shuttle-(bar) group's performance indicated that previous $(0 \%-25 \%)$ shuttleavoidance performance had a negative effect on subsequent barpress, and that (26\%-90\%) shuttle avoidance had beneficial effects.

\section{DISCUSSION}

Overall, the results tend to support the fear interference hypothesis. First, positive bar-shuttle transfer was found, indicating that rats do acquire certain avoidance information in the barpress situation and that this covert information facilitates subsequent shuttle avoidance. Second, positive shuttle-bar transfer was found, indicating that overt shuttle avoidance facilitates barpress avoidance, in spite of the interference coming from freezing and withdrawal. Third, low (i.e., up to $25 \%$ avoidance in the (shuttle)-bar group) level of performance in a previous avoidance task tends to strongly interfere with subsequent avoidance performance.

Although the present results tend to support the hypothesis that certain avoidance information acquired in a previous avoidance task facilitates subsequent avoidance, it does not answer all the questions concerning the kind of information and its quantity. Clearly, further experiments controlling for such alternative hypotheses as escape learning or CS and UCS exposure are needed (these experiments are being performed currently in my laboratory).

One question that the present experiment can answer is whether levels of previous avoidance performance are responsible for differences in subsequent avoidance. Equating percent of avoidance between previous shuttle avoidance and barpress avoidance provides us with a way to answer this question. There is an area of congruence (10\% to $26 \%$ 
avoidance) between the distribution of previous shuttle avoidance and barpress avoidance. On the average, 5 rats of the (shuttle)-bar group made $17.42 \%$ avoidance and 16 rats of the (bar)-shuttle group made $17.42 \%$ avoidance. However, the former group made only $4.16 \%$ avoidance in a subsequent barpress task, whereas the latter group made $69.74 \%$ in subsequent shuttle avoidance-a difference of $65.58 \%$. This difference is much larger than the difference of $22.8 \%$ between the (shuttle)-bar and the (bar)-shuttle control groups. Clearly, it is not the level of previous avoidance performance per se that accounts for the large differences found in subsequent avoidance.

The term latent avoidance learning cannot be applied to the shuttlebar transfer phenomenon, but only to the bar-shuttle transfer phenomenon, simply because of the high percentage of previous shuttle-avoidance performance associated with the former transfer. The low percentage of previous barpress-avoidance performance associated with the latter transfer revealed that the rat has acquired more avoidance information than meets the eye.

Finally, the present results support the approach that avoidance theory should be founded on two major groups of interacting processes: the cognitive processes, which take into account acquisition, storage, and retrieval of avoidance information, and the performance processes, which on the one hand reflect the execution of avoidance information, and on the other, are affected by such emotional reactions to the feararousing stimulus (i.e., freezing and withdrawal). This approach differs from Masterson and Crawford's (1982) proposal that cognitive learning processes are not needed for explaining avoidance behavior (however, see Masterson, 1984, for a change in the attitude toward the cognitive approach).

\section{REFERENCES}

Blanchard, R. J., \& BlanchaRd, D. C. (1969). Crouching as an index of fear. Journal of Comparative \& Physiological Psychology, 67, 370-375.

Bolles, R. D. (1975). Theory of motivation (2nd ed.). New York: Harper \& Row.

D'Amato, M., Keller, D., \& DiCara, L. (1964). Facilitation of discriminated avoidance learning by discontinuous shock. Journal of Comparative \& Physiological Psychology, 58, 344-349.
HURwitz, H. M. B. (1964). Method for discriminative avoidance learning. Science, 145, 1070-1071.

Kreickhaus, E. E., Miller, N. E., \& Zimmerman, F. (1965). Reduction of freezing behavior and improvement of shock avoidance by damphetamine. Journal of Comparative \& Physiological Psychology, 60, 36-40.

MaCKINTOSH, N. J. (1983). Conditioning and associative learning. Oxford: Clarendon Press.

Masterson, F. A. (1984). A theory of defense behavior: Innate responses, consumary goal stimuli, and cognitive expectancies. The Behavioral \& Brain Sciences, 7, 754-756.

Masterson, F. A., \& CRAWford, M. (1982). The defense motivation system: A theory of avoidance behavior. The Behavioral \& Brain Sciences, 5, 661-696.

Meyer, D. R., Cho, C., \& Weseman, A. S. (1960). On problems of conditioning discriminated lever-press avoidance response. Psychological Review, 62, 224-228.

RAKOVER, S. S. (1975). Tolerance of pain as a measure of fear. Learning \& Motivation, 6, 43-61.

RAKOVER, S. S. (1979). Fish (Tilapia aurea), as rats, learn shuttle better than lever-bumping (press) avoidance tasks: A suggestion for functionally similar universal reactions to a conditioned fear-arousing stimulus. American Journal of Psychology, 92, 489-495.

RAKOVER, S. S. (1980). Role of intertrial interval following an escape of avoidance response in bar-press avoidance. Learning \& Motivation, 22, 220-237.

RAKOVER, S. S. (1984). Avoidance theory: The nature of innate responses and their interaction with acquired responses. The Behavioral \& Brain Sciences, 7, 752-753.

\section{NOTE}

1. Because arrangements in the animal laboratory at the University of Haifa permitted 10 days of barpress avoidance and 12 days of shuttle avoidance, the statistical comparison between these tasks is based only on the first $\mathbf{1 0}$ days of shuttle avoidance.

(Manuscript received for publication April 8, 1986.) 